\title{
Assessing National Institutes of Health funding and scholarly impact in neurological surgery
}

\author{
Clinical article
}

\author{
Peter F. Svider, M.D., ${ }^{1,2,4}$ Qasim Husain, M.D., ${ }^{1}$ Adam J. Folbe, M.D., 2 \\ William T. Couldwell, M.D., Ph.D., ${ }^{3}$ James K. LiU, M.D., ${ }^{1,4,5}$ \\ AND JEAn ANDERSON ELOY, M.D. ${ }^{1,4,5}$ \\ Departments of ${ }^{I}$ Neurological Surgery, ${ }^{4}$ Otolaryngology-Head and Neck Surgery, and ${ }^{5}$ Center for Skull Base \\ and Pituitary Surgery, Rutgers New Jersey Medical School, Newark, New Jersey; ${ }^{2}$ Department of \\ Otolaryngology-Head and Neck Surgery, Wayne State University School of Medicine, Detroit, Michigan; \\ and ${ }^{3}$ Department of Neurosurgery, University of Utah, Salt Lake City, Utah
}

Object. Research productivity is increasingly important in academic neurological surgery and can be measured through a variety of methods, such as publications, objective bibliometrics, and securing external grant support. The authors' objectives were to determine whether there is an association between scholarly impact, as measured by the $h$ index, and successful National Institutes of Health (NIH) grant funding awarded to faculty in neurological surgery departments.

Methods. Primary investigators receiving National Institutes of Health (NIH) awards from Fiscal Years 20112013 were organized by academic rank, terminal degree, and their $h$ index, as calculated from the Scopus database. These data were also obtained for nonfunded faculty from 15 randomly selected departments for comparison, and the average $h$ index for each group was calculated.

Results. National Institutes of Health-funded faculty had higher average $h$ indices than their nonfunded colleagues $(23.6$ vs $10.8, \mathrm{p}<0.0001)$, a finding that persisted upon controlling for academic rank. The mean $h$ index increased with successive academic rank in both cohorts; greater funding totals were seen with successive academic position (Kruskal-Wallis, $\mathrm{p}<0.05$ ). National Institutes of Health-funded MDs had higher $h$ indices than their PhD colleagues $(\mathrm{p}=0.04)$, although funding levels did not differ significantly. There was a trend of increasing $h$ index with higher NIH-funding ranges $(\mathrm{p}<0.05)$.

Conclusions. The authors' findings demonstrate a strong relationship between scholarly impact and securing NIH funding among faculty in academic neurosurgical departments. Faculty receiving a greater amount of funding tended to have a higher $h$ index. Mean scholarly impact, as measured by the $h$ index, increased with successive academic rank among both NIH-funded and nonfunded faculty, suggesting that this bibliometric may have utility as an adjunct in the academic appointment and promotion process in academic neurological surgery.

(http://thejns.org/doi/abs/10.3171/2013.8.JNS13938)

\section{KEY WORDS - academic promotion - National Institutes of Health funding • $h$ index - scholarly impact $\bullet$ research productivity}

$\mathrm{A}$ DIVERSE array of measures may be used to evaluate academic physicians. The relative importance of the various aspects of an academician's career may differ based on his or her particular specialty and the reasons behind his or her appointment. These various facets include providing high-quality patient care, contributing

Abbreviations used in this paper: $\mathrm{NIH}=$ National Institutes of Health; PI = primary investigator. clinical income, serving in an administrative capacity, and commitment to education of residents and medical students. ${ }^{2,4,11,37}$ Another critical factor, particularly in surgical specialties, may be the scholarly impact an author has had upon the research discourse within a field. $1,7,8,33,34$ Consistently producing highly regarded research has numerous

This article contains some figures that are displayed in color online but in black-and-white in the print edition. 
benefits both to an individual and to his or her institution, and, as such, may play an important role in the academic advancement process at many institutions.

Scientific inquiry and the impact an individual has had on his or her field may be assessed in a number of ways. The number of "significant" manuscripts one has published, membership in prestigious societies, and general reputation among one's colleagues certainly may all be taken into account. ${ }^{17}$ One limitation of these measures, however, is the degree of subjectivity involved with each. Conversely, other more objective measures, such as number of citations in the literature and total number of publications, may not necessarily correlate with the quality of an author's work and the impact the author has had on his or her field. For example, the total number of citations may be disproportionately influenced by a single highly cited work. The $h$ index is a bibliometric whose use has been previously described among academic physicians in neurological surgery as well as in other specialties. ${ }^{6,7,9,10,12,21,23-27,29,31,32,35-40 ~ I t ~ h a s ~ b e e n ~ s h o w n ~ t o ~ h a v e ~}$ a strong association with scholarly impact, academic advancement, National Institutes of Health (NIH) funding procurement, and other measures of scholarly productivity. It is a widely accessible and easily calculable measure that indicates the degree to which an author is frequently cited on a regular basis, throughout his or her body of work (rather than disproportionate citation of a single work). Consequently, it is an excellent indicator of scholarly relevance.

The NIH is the preeminent funding resource in the US, and grants from this organization are considered to be very prestigious. , $11,19,22,32,39,42$ Nonetheless, there is little available evidence that this organization takes into account the scholarly impact of applicants with objective bibliometrics that assess scholarly relevance, such as the $h$ index. ${ }^{7,11,39}$ The objective of this present analysis was to determine whether there is an association between scholarly impact, as measured by the $h$ index, and successful NIH grant funding awarded to faculty in neurological surgery departments.

\section{Methods}

The NIH RePORTER website (http://projectreporter. nih.gov) was searched for awards to neurological surgery departments during the fiscal years available on this online database. There were 248 awards to 168 individuals found from Fiscal Year 2011 to Fiscal Year 2013 as of March 2013. The primary investigators (PIs), grant type, and award total were obtained. Subsequently, the online faculty listings of each individual's academic department were searched to obtain information about academic position and terminal degree (MD or equivalent, MD-PhD, and $\mathrm{PhD}$ ). Each individual's $h$ index was calculated using the Scopus database, and the average $h$ index for each group was calculated. Although there are several available $h$ index calculators, including those available from Google Scholar, Thomson Reuters Web of Knowledge, and Publish or Perish, many previous analyses have used the Scopus database, thus allowing for ease of comparison with our results. Additionally, a previous analysis of the $h$ index among neurological surgeons found a high degree of correlation between results from Google Scholar and Scopus. ${ }^{21}$ Department affiliations and source history (that is, neurosurgical or neuroscience journals) were used to ensure the appropriate entries searched for were used in this analysis.

A random number generator was used to randomly select academic neurological departments from the American Medical Association's FREIDA database. We were interested in having a similar number of nonfunded individuals for comparison, and including faculty from the first 15 programs yielded from the random number generator resulted in 166 nonfunded faculty. All non-NIH funded faculty from these programs were recorded from departmental websites and were organized by academic rank. The Scopus $h$ index was calculated for these individuals for comparison with NIH-funded faculty. Data collection was completed in March 2013.

\section{Statistical Analysis}

Mann-Whitney U-tests and Kruskal-Wallis tests were used for comparison of continuous data as appropriate, with threshold for significance set at $p<0.05$. SPSS (version 20, IBM Co.) was used for statistical analysis.

\section{Results}

There were 154 NIH-funded faculty members who were awarded a total of 234 grants included in this analysis. Of the individual awards included in this analysis, $2.4 \%$ were K08 grants, $58.1 \%$ were R01 grants, and another $18.1 \%$ were other R-series grants. National Institutes of Health-funded faculty had a higher $h$ index than their nonfunded colleagues ( $\mathrm{p}<0.0001$; Fig. 1 left). This relationship persisted upon organization by academic rank ( $\mathrm{p}<0.05$; Fig. 1 right). The $h$ index increased with successive academic rank among both NIH-funded and nonNIH funded faculty members (Kruskal-Wallis tests, $\mathrm{p}<$ 0.05 ; Fig. 1). Additionally, there was a trend toward greater funding totals with successive academic position (Kruskal-Wallis test, $p<0.05$; Fig. 2). It should be noted that the category of "non-faculty" in Fig. 2 includes 14 additional grants awarded to postdoctoral researchers, fellows, students, and other nonfaculty members in neurological surgery departments receiving NIH funding.

Upon organization by terminal degree, differences were noted in $h$ index, although this only reached statistical significance upon comparison between MDs and $\mathrm{PhDs}$ ( $p=0.04$; Fig. 3). In terms of NIH awards received, MDs had a higher mean funding level, although this did not reach statistical significance upon comparison with their MD-PhD and PhD colleagues ( $p>0.05$; Fig. 3 ). There was a trend toward increasing $h$ index with higher NIH funding range (Kruskal-Wallis test, $\mathrm{p}<0.05$; Fig. 4).

\section{Discussion}

A recent comparison of the $h$ index among academic surgeons of various specialties found that neurological surgeons, despite being the smallest specialty included in the 

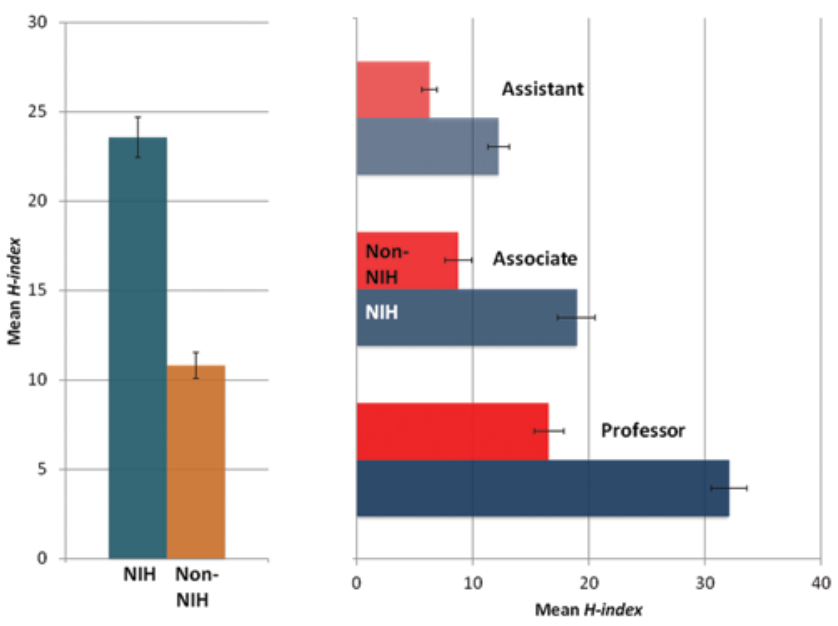

FIG. 1. Mean $h$ index of NIH-funded and nonfunded faculty in neurological surgery departments (left) further broken down by academic rank (right). Error bars represent SEM. Red bars in each pair represent non-NIH funded faculty, and bottom blue bars represent $\mathrm{NIH}$-funded faculty.

analysis, had among the highest scholarly impact. ${ }^{40}$ This is consistent with the reputation of the field as "research intensive," as the specialty has a higher degree of structured research opportunities built into residency training and beyond, relative to other surgical specialties. $5,16,20,21,40$ Although that analysis along with another study specific to neurological surgeons found an increase in scholarly impact (as measured by the $h$ index) with successive academic rank, ${ }^{21}$ no analysis has looked at how strongly this measure of scholarly productivity is associated with NIH funding procurement.

Securing grants from the NIH may enhance a department's standing within a specialty as well as within its home institution, strengthening its ability to recruit highly qualified faculty and residents. Additionally, the acquisition of external funding may allow the individual and department to make a significant scholarly impact on his or her field and free up internal mechanisms of funding for use elsewhere. Consequently, faculty who are able to secure such funding may be highly sought after by hiring committees within academic medicine.

Receiving NIH funding as a faculty member in a neurological surgery department has a strong association with scholarly impact, as NIH-funded individuals had a higher mean $h$ index even after controlling for academic rank (Fig. 1). Additionally, there is a direct association between the amount of funding such primary PIs receive and scholarly impact, as measured by the $h$ index (Fig. 4). This emphasizes our findings that the individuals in neurological surgery departments who successfully procure these highly sought after grants are the ones who contribute a greater amount of research that is consistently cited. Another important factor that should be mentioned is the significant proportion of awards that were R01 grants (58.1\%). These projects mostly involve basic science research, which by its nature may be more highly cited as the field easily crosses over into other disciplines and thus lends itself to journals with larger audiences. This is a potential con-

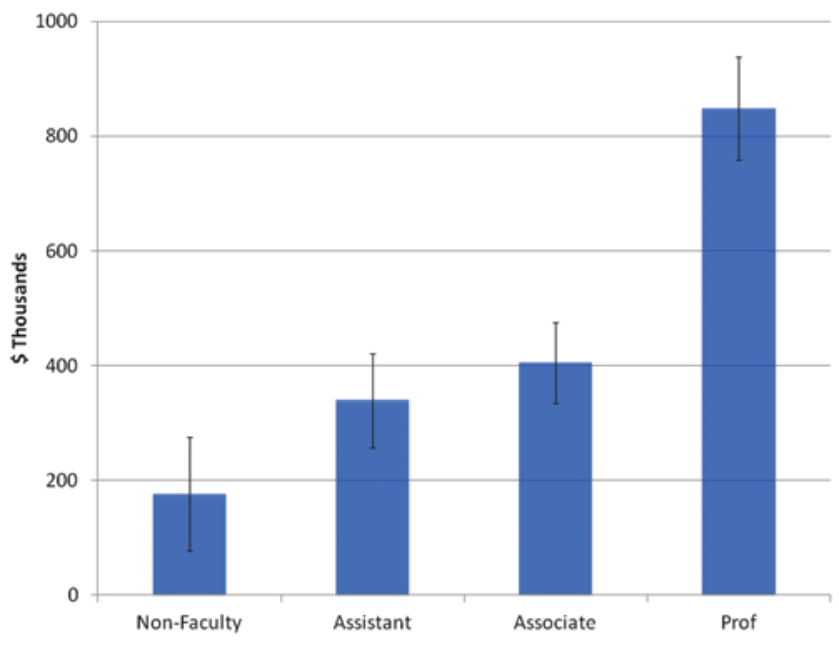

FIG. 2. Mean NIH funding organized by academic rank. Error bars represent SEM. Prof = professor.

founder in using the $h$ index to compare these faculty to other individuals included in this analysis, and stresses the importance of considering this bibliometric as an adjunct in objectively assessing an author's research productivity.

The relationship between objective bibliometrics, including the $h$ index, and NIH funding procurement has been examined among academic surgical faculty in other specialties. Colaco et al. recently found a strong relationship between NIH funding, $h$ index, and academic rank among academic urologists. ${ }^{7}$ Additionally, Svider et al. reported a similar relationship among funded and nonfunded academic otolaryngologists, noting that this objective bibliometric may have utility as an adjunct in the
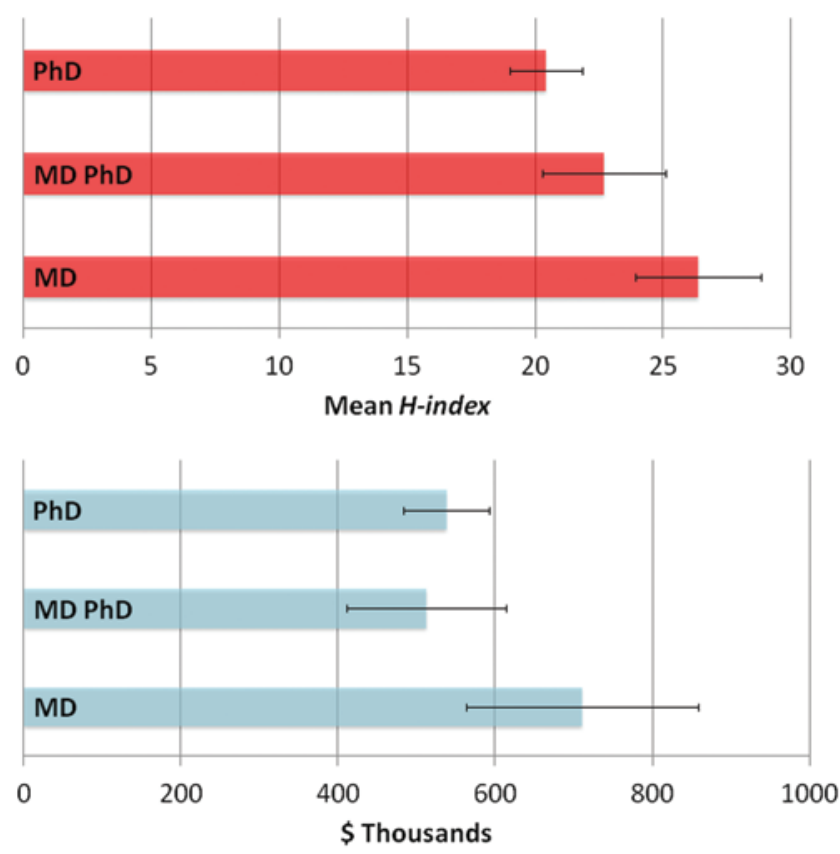

FIG. 3. Mean $h$ index (upper) and mean NIH funding (lower) of $\mathrm{NIH}$ funded faculty organized by terminal degree. Error bars represent SEM. 


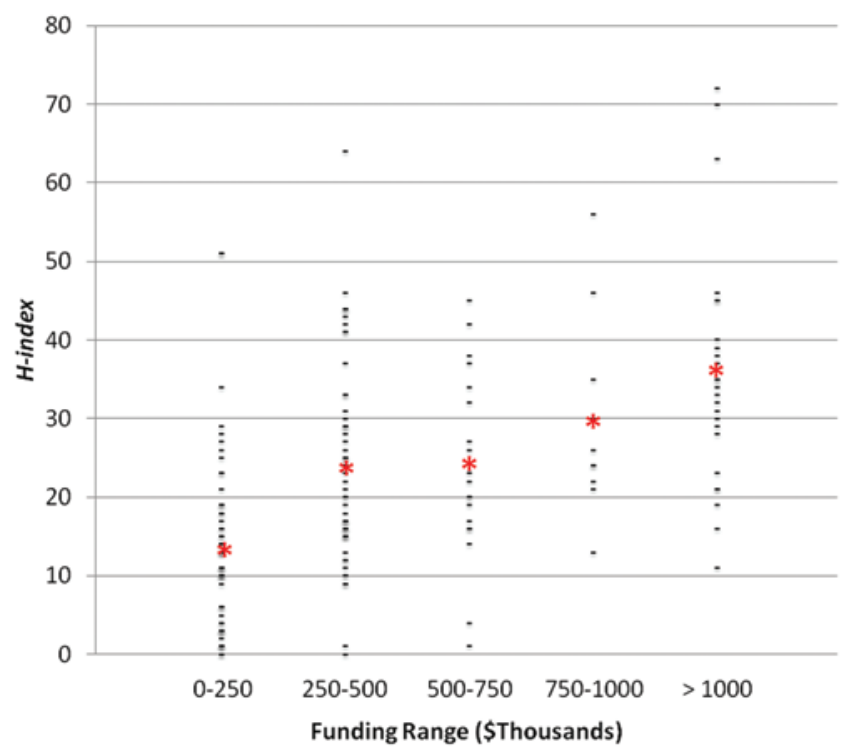

FIG. 4. Scatterplot of $h$ index organized by successive NIH funding range; the mean $h$ index is indicated by asterisks.

academic advancement process among faculty in either cohort. ${ }^{37}$ Although these findings were similar to those in the current analysis, one interesting area of difference relates to the terminal degree an NIH-funded faculty member possesses. Similar to our findings among neurological surgeons (Fig. 3), funded otolaryngology faculty with MD degrees had higher scholarly impact than their colleagues with a PhD; in contrast, no difference was noted upon organization by degree among academic urologists. This potentially illustrates that the chances MD faculty members have for becoming involved in academic research may differ within various surgical specialties, and may in fact be higher in otolaryngology and neurological surgery than in other specialties. Possible factors involved in these decisions may be the pressures for faculty to contribute clinical income, the availability of protected research time, and the general emphasis a specialty places on research productivity. Further characterization of the impact of NIH funding on research productivity in other surgical specialties may be needed to fully address this issue.

Although this is the first examination to characterize the relationship between scholarly impact, using an objective bibliometric such as the $h$ index and NIH funding in neurological surgery, there are several limitations inherent to this study. Very few neurosurgical faculty listings distinguish between tenure track versus non-tenure track faculty, a limitation that mostly affects nonclinical faculty. Controlling for this may influence our results; for example, research-focused faculty (that is, the ones obtaining NIH funding) may be more likely to be tenured faculty. Our inclusion criteria for this analysis involved all full-time "academic" faculty included on these sites.

Another drawback to this analysis regards the study design. We cannot attribute causation, as it is impossible to say whether individuals with higher scholarly impact are more likely to be successfully awarded grants, or whether those with larger grants are more likely to produce im- pactful and consistently cited research. Both of these conclusions are purely speculative, and future analysis with a prospective design may be needed to answer this question. Nonetheless, our findings indicate a strong relationship between these variables and stress that the $h$ index is an objective bibliometric that has utility in assessing a faculty member's performance. In the future, funding organizations such as the NIH may consider using such objective bibliometrics to better assess whether applicants may potentially produce impactful research.

A potential confounder in this analysis may be that the prestige associated with earning NIH awards may make readers more likely to cite NIH-funded findings by virtue of their funding source rather than the quality of the findings; this NIH funding paradigm may promote citation practices that end up inflating these individuals' $h$ indices without a comprehensive examination of the quality of their work. Although this is certainly a possibility, we would like to emphasize that this is purely speculative and certainly outside the scope of this analysis.

Another potential limitation of this analysis is the use of the $h$ index. There certainly are drawbacks to reliance on a single measure of achievement, and it should be emphasized that we are suggesting that this measure may have utility as an adjunct in the academic appointment and promotion process when considering scholarly impact. A previously noted limitation of the $h$ index regards its inability to distinguish between the types of research an individual conducts. For example, practitioners focusing on basic and translational science-oriented projects likely submit their findings to higher impact journals, as this type of scholarship has more potential for cross-disciplinary interest. This likely leads to a more direct path to having higher scholarly impact, as measured by the $h$ index. As NIH-funded researchers likely focus on these types of projects, this issue has the potential to be a confounding factor. Conversely, many of these types of projects require a very labor- and time-intensive approach. As a result, a non-basic science researcher, such as an individual focusing on retrospective clinical data, may have an opportunity to produce a higher volume of publications, albeit to journals with smaller audiences. The effect of these dynamics is unclear but should certainly be kept in mind, as these issues highlight that objective bibliometrics such as the $h$ index are optimally used as an adjunct when evaluating an individual's scholarly output, and should be considered in the full context of an author's work. These issues and other potential limitations of the $h$ index have been widely reported in the literature. $3,7,9,10,12-15,18,23,25,26,28-30,35,39-41$ Despite these known limitations, the $h$ index is an objective measure that takes into account the frequency with which a faculty member has had an impact upon scholarly discourse within a field and has been shown in many analyses to have a strong association with academic promotion, receiving external funding, graduate medical education, and a variety of other factors measuring achievement.

\section{Conclusions}

Our findings demonstrate a strong relationship between scholarly impact and procurement of NIH funding 
among faculty in academic neurosurgical departments. National Institutes of Health-funded faculty had higher research productivity than their nonfunded colleagues, a relationship that persisted upon controlling for academic rank. Faculty receiving a greater amount of funding tended to have a higher $h$ index. Mean scholarly impact, as measured by the $h$ index, increased with successive academic rank among both NIH-funded and nonfunded faculty, suggesting that this bibliometric may have utility as an adjunct in the academic appointment and promotion process in academic neurological surgery.

\section{Disclosure}

The authors report no conflict of interest concerning the materials or methods used in this study or the findings specified in this paper.

Author contributions to the study and manuscript preparation include the following. Conception and design: Liu, Eloy. Acquisition of data: Svider, Husain. Analysis and interpretation of data: Svider, Husain, Eloy. Drafting the article: Svider. Critically revising the article: all authors. Reviewed submitted version of manuscript: all authors. Approved the final version of the manuscript on behalf of all authors: Liu. Statistical analysis: Svider, Husain. Administrative/technical/material support: Folbe, Eloy. Study supervision: Liu, Couldwell, Eloy.

\section{References}

1. Addona T, Polcino M, Silver L, Taub PJ: Leadership trends in plastic surgery. Plast Reconstr Surg 123:750-753, 2009

2. Baldwin C, Chandran L, Gusic M: Guidelines for evaluating the educational performance of medical school faculty: priming a national conversation. Teach Learn Med 23:285-297, 2011

3. Benway BM, Kalidas P, Cabello JM, Bhayani SB: Does citation analysis reveal association between $\mathrm{h}$-index and academic rank in urology? Urology 74:30-33, 2009

4. Bligh J, Brice J: Further insights into the roles of the medical educator: the importance of scholarly management. Acad Med 84:1161-1165, 2009

5. Burnett MG, Stein SC, Grady MS: What we research: survey of American Association of Neurological Surgeons and Congress of Neurological Surgeons member publications. J Neurosurg 100:73-78, 2004

6. Castillo M: Measuring academic output: the H-index. AJNR Am J Neuroradiol 31:783-784, 2010

7. Colaco M, Svider PF, Mauro KM, Eloy JA, Jackson-Rosario I: Is there a relationship between National Institutes of Health funding and research impact on academic urology? J Urol 190:999-1003, 2013

8. Dixon AK: Publishing and academic promotion. Singapore Med J 50:847-850, 2009

9. Eloy JA, Svider P, Chandrasekhar SS, Husain Q, Mauro KM, Setzen M, et al: Gender disparities in scholarly productivity within academic otolaryngology departments. Otolaryngol Head Neck Surg 148:215-222, 2013

10. Eloy JA, Svider PF, Cherla DV, Diaz L, Kovalerchik O, Mauro $\mathrm{KM}$, et al: Gender disparities in research productivity among 9,952 academic physicians. Laryngoscope 123:1865-1875, 2013

11. Eloy JA, Svider PF, Kovalerchik O, Baredes S, Kalyoussef E, Chandrasekhar SS: Gender differences in successful NIH grant funding in otolaryngology. Otolaryngol Head Neck Surg 149:77-83, 2013

12. Eloy JA, Svider PF, Mauro KM, Setzen M, Baredes S: Impact of fellowship training on research productivity in academic otolaryngology. Laryngoscope 122:2690-2694, 2012
13. Eloy JA, Svider PF, Patel D, Setzen M, Baredes S: Comparison of plaintiff and defendant expert witness qualification in malpractice litigation in otolaryngology. Otolaryngol Head Neck Surg 148:764-769, 2013

14. Engqvist L, Frommen JG: The h-index and self-citations. Trends Ecol Evol 23:250-252, 2008

15. Gaster N, Gaster M: A critical assessment of the h-index. Bioessays 34:830-832, 2012

16. Hauptman JS, Chow DS, Martin NA, Itagaki MW: Research productivity in neurosurgery: trends in globalization, scientific focus, and funding. A review. J Neurosurg 115:1262-1272, 2011

17. Hirsch JE: An index to quantify an individual's scientific research output. Proc Natl Acad Sci U S A 102:16569-16572, 2005

18. Jeang KT: H-index, mentoring-index, highly-cited and highly-accessed: how to evaluate scientists? Retrovirology 5:106, 2008

19. Kotchen TA, Lindquist T, Malik K, Ehrenfeld E: NIH peer review of grant applications for clinical research. JAMA 291: 836-843, 2004

20. Langfitt TW: Research and training in the neurosurgical sciences. With comments on some key issues that confront neurosurgery. A review. J Neurosurg 57:733-738, 1982

21. Lee J, Kraus KL, Couldwell WT: Use of the $h$ index in neurosurgery. Clinical article. J Neurosurg 111:387-392, 2009

22. National Institutes of Health Office of Extramural Research: Peer Review Process. (http://grants.nih.gov/grants/peer review_process.htm) [Accessed September 3, 2013]

23. Pagel PS, Hudetz JA: An analysis of scholarly productivity in United States academic anaesthesiologists by citation bibliometrics. Anaesthesia 66:873-878, 2011

24. Pagel PS, Hudetz JA: Bibliometric analysis of anaesthesia journal editorial board members: correlation between journal impact factor and the median h-index of its board members. Br J Anaesth 107:357-361, 2011

25. Pagel PS, Hudetz JA: H-index is a sensitive indicator of academic activity in highly productive anaesthesiologists: results of a bibliometric analysis. Acta Anaesthesiol Scand 55:10851089, 2011

26. Pagel PS, Hudetz JA: Scholarly productivity of United States academic cardiothoracic anesthesiologists: influence of fellowship accreditation and transesophageal echocardiographic credentials on h-index and other citation bibliometrics. J Cardiothorac Vasc Anesth 25:761-765, 2011

27. Pashkova AA, Svider PF, Chang CY, Diaz L, Eloy JA, Eloy JD: Gender disparity among US anaesthesiologists: are women underrepresented in academic ranks and scholarly productivity? Acta Anaesthesiol Scand 57:1058-1064, 2013

28. Patro BK, Aggarwal AK: How honest is the h-index in measuring individual research output? J Postgrad Med 57:264-265, 2011

29. Poynard T, Thabut D, Jabre P, Munteanu M, Ratziu V, Benhamou Y, et al: Ranking hepatologists: which Hirsch's h-index to prevent the "e-crise de foi-e"? Clin Res Hepatol Gastroenterol 35:375-386, 2011

30. Quigley MR, Holliday EB, Fuller CD, Choi M, Thomas CR Jr: Distribution of the h-index in radiation oncology conforms to a variation of power law: implications for assessing academic productivity. J Cancer Educ 27:463-466, 2012

31. Rad AE, Brinjikji W, Cloft HJ, Kallmes DF: The H-index in academic radiology. Acad Radiol 17:817-821, 2010

32. Rezek I, McDonald RJ, Kallmes DF: Is the h-index predictive of greater NIH funding success among academic radiologists? Acad Radiol 18:1337-1340, 2011

33. Sanfey H: Promotion to professor: a career development resource. Am J Surg 200:554-557, 2010

34. Sanfey H, Gantt NL: Career development resource: academic career in surgical education. Am J Surg 204:126-129, 2012 
35. Sharma B, Boet S, Grantcharov T, Shin E, Barrowman NJ, Bould MD: The h-index outperforms other bibliometrics in the assessment of research performance in general surgery: a province-wide study. Surgery 153:493-501, 2013

36. Svider PF, Blake DM, Setzen M, Folbe AJ, Baredes S, Eloy JA: Rhinology fellowship training and its scholarly impact. Am J Rhinol Allergy 27:e131-e134, 2013

37. Svider PF, Choudhry ZA, Choudhry OJ, Baredes S, Liu JK, Eloy JA: The use of the h-index in academic otolaryngology. Laryngoscope 123:103-106, 2013

38. Svider PF, Mady LJ, Husain Q, Sikora AG, Setzen M, Baredes $\mathrm{S}$, et al: Geographic differences in academic promotion practices, fellowship training, and scholarly impact. Am J Otolaryngol 34:464-470, 2013

39. Svider PF, Mauro KM, Sanghvi S, Setzen M, Baredes S, Eloy JA: Is NIH funding predictive of greater research productivity and impact among academic otolaryngologists? Laryngoscope 123:118-122, 2013

40. Svider PF, Pashkova AA, Choudhry Z, Agarwal N, Kovalerchik O, Baredes S, et al: Comparison of scholarly impact among surgical specialties: an examination of 2429 academic surgeons. Laryngoscope 123:884-889, 2013

41. Turaga KK, Gamblin TC: Measuring the surgical academic output of an institution: the "institutional" H-index. J Surg Educ 69:499-503, 2012

42. Zerhouni EA: From the desk of the NIH director: Reviewing Peer Review: NIH needs your help! (http://www.nih.gov/ about/director/newsletter/Summer2007.htm) [Accessed September 3, 2013]

Manuscript submitted May 7, 2013.

Accepted August 29, 2013.

Please include this information when citing this paper: published online November 12, 2013; DOI: 10.3171/2013.8.JNS13938.

Address correspondence to: James K. Liu, M.D., Department of Neurological Surgery, Rutgers New Jersey Medical School, 90 Bergen St., Ste. 8100, Newark, NJ 07103. email: james.liu.md@ rutgers.edu. 